\title{
Keep the Expert! Occupational Expertise, Perceived Employability and Job Search: A
}

\section{Study across Age Groups}

Ans De Vos (Antwerp Management School and Faculty of Applied Economic Sciences, University of Antwerp, Antwerp, Belgium)

Anneleen Forrier (Faculty of Economics and Business, KU Leuven, Antwerp, Belgium)

Beatrice Van der Heijden (Institute for Management Research, Radboud University Nijmegen, Nijmegen, The Netherlands; Open University of The Netherlands, Heerlen, The Netherlands and Kingston University, London, UK)

Nele De Cuyper (Department of Occupational and Organisational Psychology and Professional Learning, KU Leuven, Leuven, Belgium)

\begin{abstract}
Purpose: In the current war for talent employers are concerned about the idea that the best employees are more likely to leave the organization for another employer (i.e. the management paradox). This study tests this management paradox. It aims to advance our understandings of how employees' occupational expertise is associated with job search intensity, through its assumed relationships with perceived employability in the internal and the external labor market. We tested our research model across three different age groups (young, middle-aged and senior employees).
\end{abstract}

Design/Methodology/Approach: We conducted a survey among 2,137 professional workers and applied multi-group structural equation modeling.

Findings: Perceived internal employability negatively mediated the relationship between occupational expertise and job search intensity, whilst there was a positive mediational effect 
of perceived external employability. Age had a moderating effect on the association between perceived internal employability and job search intensity.

Research Implications: Our findings contribute to the scholarly literature on the management paradox and the empirical work on employability and age.

Practical Implications: Organizations can recoup their investments in expert workers' employability and enhance their retention by providing opportunities for internal career development.

Originality/Value: This study is original by including both internal and external employability. By doing so, we shed new light on how occupational expertise might explain job search and how this relationship differs depending on employee age.

Key words: Occupational expertise; Perceived internal employability; Perceived external employability; Job search intensity; Moderating role of age. 


\section{Keep the Expert! Occupational Expertise, Perceived Employability and Job Search: A}

\section{Study across Age Groups}

Occupational expertise, i.e., having the necessary competences to perform well in a particular domain of work, is crucial in the current knowledge economy (Van der Heijde and Van der Heijden, 2006; Van der Heijden et al., 2009). For employers, occupational expertise entails possibilities for optimal allocation of labor and enhanced performance and flexibility (Van der Heijde and Van der Heijden, 2006; Van der Heijden, 2002). For employees, especially professionals, occupational expertise may strengthen their employability, not only in the internal but also in the external labor market (Forrier and Sels, 2003; Van der Heijden, 2002).

Perspectives of employers and employees may appear conflicting in many circumstances. Employers may aim to retain employees with high occupational expertise, while employees may want to capitalize on their expertise by searching for challenging and/or more rewarding jobs elsewhere. This is exacerbated in the ongoing war for talent which prompts concerns related to the so-called management paradox (De Cuyper and De Witte, 2011); employers may be willing to invest in the development of their workers' expertise at the risk of losing these workers to competing organizations before they can recoup their investments. Ideas related to the management paradox are widespread among practitioners, however, they are not often tested empirically nor challenged.

In response to this gap in the scholarly literature, we address the relationship between occupational expertise and job search. Job search is one of the strongest predictors of actual turnover (Griffeth et al., 2000) and appears to have more predictive validity than attitudinal outcomes like commitment and turnover intention that were used in earlier studies on the management paradox (De Cuyper and De Witte, 2011; De Cuyper et al., 2011). More specifically, we focus on job search intensity, i.e., the frequency with which job seekers engage in preparatory and active job search activities (Blau, 1994). 
In testing the relationship between occupational expertise and job search intensity, we expose the management paradox in two ways. First, this paradox may be less problematic than assumed if one considers employees' perceptions regarding their employment opportunities on the internal and the external labor market, i.e., perceived internal employability and perceived external employability, in this association. Occupational expertise might trigger job search because expert employees may perceive attractive opportunities outside their current organization and hence act upon their perceived external employability. Yet it may also prevent job search because expert employees may feel valuable to their current employer and hence act upon their perceived internal employability.

Second, the management paradox may be conditional upon age. With an increase in age, achievement motivation may shift from a more extrinsic, competitive pattern of achievement to a more intrinsic, mastery-related pattern (Maehr and Kleiber, 1981). Moreover, as employees grow older, they may become more bounded to their current organization due to family issues such as dual career couples or aging parents (Feldman, 2007). Therefore, younger employees may be more likely to act upon self-evaluations of employability compared with their older counterparts as younger employees may pursue growth while older employees may find satisfaction in present relationships at work and generativity (Neugarten, 1977). Incorporating an age perspective is especially relevant given the greying working population and increased age diversity in the workforce (European Commission, 2015). It is also reflected in the idea that HR-practices should be tailored to employee age. Surprisingly, age in most studies has only been included as a control variable (Schalk et al., 2010). In this study, we probe whether relationships between occupational expertise, perceived internal employability and perceived external employability, and job search intensity vary with age through multigroup analysis. 


\section{THEORY AND HYPOTHESES}

\section{Perceived occupational expertise, perceived internal and external employability, and job}

\section{search intensity}

Occupational expertise is broadly defined as having the necessary competences to perform well in a specific work-related domain (Van der Heijde and Van der Heijden, 2006). It comprises domain-specific knowledge and skills that are needed to deliver high-quality work as well as meta-cognitive knowledge and skills, i.e., self-consciousness about one's strengths and weaknesses. Occupational expertise has mostly been assessed in the form of self-reports (for exceptions see Van der Heijden et al., 2009; Van der Heijden et al., 2016). We hypothesize that perceived occupational expertise is related to job search intensity and that this relationship is partially mediated by perceived employability. Occupational expertise fits the so-called 'inputbased" approach of employability (Wittekind et al., 2010), which focuses on personal strengths that increase the chance of obtaining a job in the internal or external labor market (Forrier and Sels, 2003; Vanhercke et al., 2014). In contrast, perceived employability fits the "output-based" approach, which focuses on employees' subjective appraisals of their alternative employment opportunities (De Vos et al., 2011; Forrier and Sels, 2003; Vanhercke et al., 2014). Few studies have dealt with the relationship between input-based and outcome-based approaches of employability (see Forrier et al., 2015; Wittekind et al., 2010 for exceptions).

To more fully understand whether occupational expertise may lead to job search intensity, via perceived employability, it is important to distinguish between perceived internal employability and perceived external employability as both differ in focus and in scope, which might lead to two opposing mediating processes. Whilst PIE focuses on employment opportunities in the internal labor market, perceived internal employability comprises opportunities in the external labor market, which implies a broader scope of opportunities in comparison with PIE (e.g., De Cuyper and De Witte, 2011; Forrier and Sels, 2003; Forrier et 
al., 2009; Rothwell and Arnold, 2007; Vanhercke et al., 2014). Occupational expertise is likely to positively affect perceived internal employability and perceived external employability, but in turn both will trigger opposing processes as regards job search intensity.

First, building on the career competencies framework put forward by Arthur et al. (1995), we expect that occupational expertise will be positively associated with workers' perceived internal employability. The "knowing how" component of career competencies includes the knowledge and skills that individuals bring to the organization through formal and experiental learning (Eby et al., 2003; Williams et al., 2015). Seen from this perspective, perceived occupational expertise is part of individuals' movement capital (Forrier et al., 2015) and it entails their perceptions of the added functionality they provide to their current employer through their skills and knowledge (Williams et al., 2015). Employees scoring high on occupational expertise will perceive more internal career opportunities because their expertise provides them with access to a broader range of internal career options (DeFillippi and Arthur, 1996).

Organizations may use internal career opportunities as a strategy to bind employees with high expertise so that they perceive more opportunities in the internal labor market and are more confident about future internal employment opportunities. This, in turn, may reduce the likelihood that these employees will engage in job search behaviors outside their organization for two reasons. First, employees who feel valuable within their present environment and hence have a high level of perceived internal employability may not feel the need to explore other options in the external labor market, as they may feel that their career goals can be realized within their current organization (De Cuyper et al., 2011; Nauta et al., 2009). Second, employees who do not feel valuable within their current organization, and thus have a low level of perceived internal employability, may be more likely to engage in job search as an adaptive career strategy. According to the model of approach and avoidance achievement 
motivation (Elliot, 2005), people define, experience, and respond to competence-relevant situations, including the workplace, depending upon the goals they want to attain. People disengage from a goal if they are unlikely to attain that goal, implying that employees may disengage from the goal of building a career within their current organization in case of low perceived internal employability, which, in turn, might result in more job search. We therefore expect a negative mediation effect for perceived internal employability:

Hypothesis 1: The negative relationship between perceived occupational expertise and job search will be mediated by perceived internal employability.

Second, for perceived external employability we expect a positive mediation effect. Specifically, the work domain for which employees with a high amount of occupational expertise consider themselves to be competent is in most cases not restricted to their current organization (Arthur et al., 1995). A high degree of expertise also signals employees' productivity potential to other employers, making these employees also more attractive on the external labor market (Eby et al., 2003). Therefore, they may also be more confident about future employment opportunities in the external labor market, which, in turn, will result in a more intense job search. From a motivational perspective, and following expectancy theory, in particular (Vroom, 1964), employees are more likely to engage in job search activities if they believe that this effort will lead to rewarding outcomes in the future. Workers who feel employable in the external labor market, thus having a high level of perceived external employability, do believe that transition opportunities to an alternative job are available and attainable, and they may therefore engage in more job search activities. Indirect evidence in support of this relationship can be found in research indicating that the perceived quantity and quality of job alternatives predict both intent to search and actual job search (Griffeth et al., 2005). In contrast, employees will be less inclined to put effort in something if they assume 
that this effort will not lead to rewarding outcomes. So, employees who do not feel valuable to other employers, and thus have a low level of perceived external employability, may be less likely to engage in job search.

Hypothesis 2: The positive relationship between perceived occupational expertise and job search will be mediated by perceived external employability.

\section{The moderating role of age group}

We expect that age will moderate some of the relationships in our model, in particular the associations of perceived internal employability and perceived external employability with job search intensity. We thereby consider three age categories based upon the thresholds commonly used in the literature (Peeters and Van Emmerik, 2008): younger ( $<35$ years), middle-aged (3549), and senior ( $\geq 50$ years) employees, which correspond to the early-, mid- and late career phase (Hunt and Collins, 1983; Van der Heijden, 2001).

Although employees' perceptions of their occupational expertise (Orth et al., 2011; Van der Heijden, 2000) and of their perceived employability (De Coen, Forrier, and Sels, 2015) may vary with age, we do not expect the relationship between both variables to be agedependent-. Concerning the relationship between perceived employability and job search intensity, however, we do expect age differences. Based on socio-emotional selectivity theory (Carstensen et al., 1999), we expect that older individuals will act differently on their perceived employability compared to their younger counterparts. Socio-emotional selectivity theory states that there is a shift from knowledge-related goals aimed at learning and growth towards emotional goals aimed at emotion regulation and social embeddedness across the lifespan. Therefore, employees in their early career phase are presumed to attach more importance to growth but then gradually shift their attention to social relationships at work ( $\mathrm{Ng}$ and Feldman, 2009). Results of a meta-analysis indeed support this argument (Kooij et al., 2011). 
Applied to perceived internal employability, this would imply that a lack of perceived opportunities within one's current organization may be a stronger trigger for job search for younger than for older workers. In comparison, a lack of perceived internal employment opportunities is not incompatible with the wish for greater social embeddedness, and hence not necessarily a trigger for job search among older employees. In addition, the fact that the occupational future time perspective of older individuals is more limited (Bal et al., 2013), may lead them to focus more on present-oriented goals that maximize emotional meaning rather than on goals that optimize the future.

The same reasoning holds for perceived external employability. Younger employees who perceive a higher degree of external employability may be more likely to feel the need to act upon perceived external employment opportunities in view of pursuing growth in their career compared to older employees. On the contrary, the latter may find more satisfaction in long-established networks and the emotional bond they have established with their current working environment.

Hypothesis 3: Age will moderate the negative relationship between perceived internal employability and job search intensity, such that the strength of the negative relationship will be higher for younger employees than for older employees.

Hypothesis 4: Age will moderate the positive relationship between perceived internal employability and job search intensity, such that the strength of the positive relationship will be higher for younger employees than for older employees.

\section{METHOD}

\section{Sample and Procedure}

Data were collected using an online survey which was widely distributed in collaboration with a Flemish career magazine targeting professional workers in various occupational fields and 
sectors. Initially, 3,924 respondents filled out the questionnaire, yet self-employed and unemployed respondents, company owners and those with missing values on the study variables were excluded from the analyses, leaving 2,137 usable questionnaires. Of this final sample, $51.3 \%$ were male, $82.8 \%$ held a bachelor's or master's degree, $68.8 \%$ were employed as professional employees and $31.2 \%$ worked at a management level. Seventy-five percent came from the private sector and $24.9 \%$ from the public/non-profit sector. Their average age was 36 years $(S D=9.05)$. We categorized respondents into three groups based on their calendar age: (1) younger than 35 years $(\mathrm{N}=1,003)$; (2) between 35 and 49 years $(\mathrm{N}=893)$; and (3) 50 years or older $(\mathrm{N}=241)$.

\section{Measures}

Data were obtained using self-assessment questionnaires. All scales were taken from standardized instruments that were found reliable in earlier studies and in various samples.

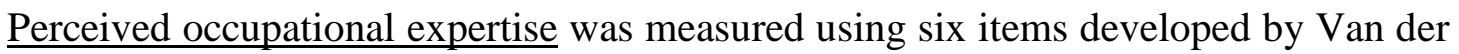
Heijde and Van der Heijden (2006), which assesses employees' beliefs in their capabilities and expertise (domain-related knowledge and skills and meta-cognitive skills) to adequately perform various tasks and to carry out the responsibilities of a job (e.g., "I consider myself competent to provide information on my work in a way that is comprehensible."). All items were scored on a five-point rating scale ranging from $1=$ "Not at all", to $5=$ "Extremely". (Cronbach's $\alpha$ in this study was .79).

Perceived internal employability was assessed with the three-item scale developed by Eby et al. (2003). A sample item is: "There are many opportunities available for me in my company.". All items were scored on a five-point rating scale ranging from 1 = "Strongly disagree" to $5=$ "Strongly agree" (Cronbach's $\alpha=.76)$. 
Perceived external employability was assessed using the three item-scale developed by Eby et al. (2003). A sample item is: "I could easily obtain a comparable job with another employer.". All items were scored on a five-point rating scale, ranging from 1 = "Strongly disagree" to 5 = "Strongly agree" (Cronbach's $\alpha=.67)$.

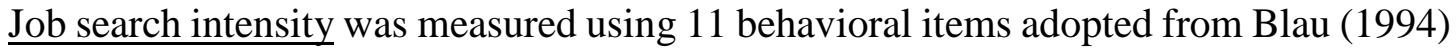
and Chen and Lim (2012). Consistent with the original scale instructions, respondents had to indicate the frequency with which they had carried out each behavioral item within the last six months (e.g., "contacting a potential employer") on a five-point rating scale, ranging from $1=$ "Never" to $5=$ "Very frequently". For the purpose of this study all items were collapsed into one global job search intensity scale (Cronbach's $\alpha=.92)$.

Control variables. In our analyses, we statistically controlled for gender, educational qualification, tenure, and occupational position, as these personal factors might predict employees' job search behaviors (e.g., Van Hooft, Born, Taris, Flier, and Blonk, 2004).

\section{Analyses}

We applied Structural Equation Modeling (SEM) using the maximum likelihood method with the SPSS AMOS software package (Arbuckle, 2007) following a four-step procedure. First, we compared different measurement models for the total sample: the hypothesized four-factor model (perceived occupational expertise, perceived internal employability, perceived external employability, and job search intensity), a three-factor model in which the items for perceived internal employability and perceived external employability were lumped together, and a onefactor model in which all items loaded together on one factor. We then tested for configural and factorial invariance of the best fitting measurement model across the subsamples of younger $(<35$ years; $N=1,003)$, middle-aged $(35-49$ years; $N=893)$ and senior employees $(>$ 49 years; $N=241$ ). In case factorial invariance was not achieved, we inspected which factor loadings caused differences across the subsamples through an iterative process in which factor 
loadings were freed one by one. Third, we tested the structural model in line with the research model with paths from perceived occupational expertise to both perceived internal employability and perceived external employability, and from and perceived external employability to job search intensity. We compared this model to a model wherein a direct path from perceived occupational expertise to job search intensity was added. Finally, we performed a multi-group analysis to evaluate whether relationships differed according to age. We compared the unconstrained (i.e., path coefficients can vary freely across the groups) and constrained model (i.e., path coefficients are constrained equal across the age groups), and we continued with a more detailed inspection of path coefficients that were allowed to differ across the groups following an iterative process. We performed the analyses with and without control variables (gender, educational qualification, tenure, and occupational position). As the pattern of results was essentially identical, we present the results without control variables, in line with the recommendations by Spector and Brannick (2011) and Carlson and Wu (2012).

Model fit was evaluated using the Comparative Fit Index (CFI), the Root Mean Square Error of Approximation (RMSEA), and the Standardized Root Mean Square Residual (SRMR). Indications of an acceptable fit are CFI $>.90$, RMSEA and SRMR $<.10$, and a good fit when CFI > .95 and RMSEA and SRMR < .06 (Hu and Bentler, 1999). Nested models were compared with the $\chi^{2}$ difference test.

\section{RESULTS}

Table 1 presents means, standard deviations and correlations between the study variables for the total sample and the subsamples.

--- Insert Table 1 About Here ---

\section{Measurement models}


Total sample. We first tested the hypothesized measurement model (MM1) with four latent factors (perceived occupational expertise, perceived internal employability, perceived external employability, and job search intensity) for the total sample (see Table 2; upper part). This model fit the data well, $\chi^{2}(129)=622.97, p<.000, \mathrm{CFI}=.97, \mathrm{RMSEA}=.04, \mathrm{SRMR}=.03$. All items loaded significantly and in the expected direction on their respective latent factors, $M_{\text {standardized loadings }}=.71$, range $_{\text {standardized loadings }}=[.48, .88]$. The hypothesized model fit the data better than the alternative three-factor model $(\mathrm{MM} 2), \chi^{2}(132)=1471.58, p<.000, \mathrm{CFI}=.92$, $\mathrm{RMSEA}=.07, \mathrm{SRMR}=.07, \Delta \chi^{2}(3)=848.61, p<.000$ and the one-factor model $(\mathrm{MM} 3), \chi^{2}$ $(135)=11421.32, p<.000, \mathrm{CFI}=.52, \mathrm{RMSEA}=.20, \mathrm{SRMR}=.21, \Delta \chi^{2}(6)=10798.35, p<$ .000 .

--- Insert Table 2 About Here ---

Subsamples. We continued with a test of factorial invariance across the subsamples (see Table 2; lower part). The configural model with unconstrained factor loadings (MM4) yielded a good fit to the data, $\chi^{2}(387)=935.38, p<.000, \mathrm{CFI}=.97, \mathrm{RMSEA}=.03, \mathrm{SRMR}=.04$. The factorial invariance model in which all factor loadings were constrained equal across the subsamples $(\mathrm{MM})$ fitted the data significantly worse, $\chi^{2}(415)=1004.58, p<.000, \mathrm{CFI}=.96$, $\mathrm{RMSEA}=.03, \mathrm{SRMR}=.04, \Delta \chi^{2}(28)=69.2, p<.000$. We freed the parameters from the fully constrained model one by one to inspect which parameter(s) accounted for not achieving factorial invariance. When model fit did not improve, parameter constraints were retained. This led to a model with unconstrained factor loadings for three items, all of them loading on the latent factor perceived occupational expertise (MM6): the factor loadings of two items were different across the three subsamples, and for one item they differed across two subsamples. This model provided a good fit to the data, $\chi^{2}(409)=974.31, p<.000$, CFI $=.97$, RMSEA $=$ $.03, \mathrm{SRMR}=.04$, which was not significantly worse than the fully unconstrained model, $\Delta \chi^{2}$ $(22)=38.93, p=.014$ 


\section{Test of hypotheses}

Total sample. The structural model with direct and indirect (i.e., through perceived employability) paths from perceived occupational expertise to job search intensity (SM1) yielded a good fit to the data, $\chi^{2}(130)=733.10, p<.000, \mathrm{CFI}=.96, \mathrm{RMSEA}=.05, \mathrm{SRMR}=$ .04. However, this model did not fit the data better compared with a more parsimonious model without the direct path $(\mathrm{SM} 2), \chi^{2}(131)=733.37, p<.000, \mathrm{CFI}=.96, \mathrm{RMSEA}=.05, \mathrm{SRMR}$ $=.04, \Delta \chi^{2}(1)=.27, p=.60$ (see Table 3 ). This suggests that the path from perceived occupational expertise to job search intensity was indirect through perceived internal employability and perceived external employability, which supports our theoretical model.

--- Insert Table 3 About Here ---

Figure 1 shows the coefficients for the total sample for the model without the direct path from perceived occupational expertise to job search intensity. Perceived occupational expertise was positively related to both perceived internal employability $(\gamma=.48, p<.001)$ and perceived external employability $(\gamma=.67, p<.001)$. In turn, perceived internal employability related negatively to job search intensity $(\gamma=-.25, p<.001)$, whilst perceived external employability related positively to job search intensity $(\gamma=.19, p<.001)$. This supported Hypotheses 1 and 2.

\section{--- Insert Figure 1 About Here ---}

Subsamples. The model without the direct path was taken as input for the multi-group analysis. We found that the model in which all path coefficients could vary freely (SM4) yielded a good fit to the data, $\chi^{2}(415)=1086.85, p<.000, \mathrm{CFI}=.96, \mathrm{RMSEA}=.03$, SRMR $=.04$. The model in which all path coefficients were constrained equal (SM5) appeared to have a significantly worse fit, $\chi^{2}(415)=1109.56, p<.000, \mathrm{CFI}=.96, \mathrm{RMSEA}=.03, \mathrm{SRMR}=.04$, $\Delta \chi^{2}(8)=22.71, p<.01$. We followed the iterative process, now with respect to the path coefficients, leading to a final model in which the path from perceived internal employability 
to job search intensity was different across the subsamples (SM6), $\chi^{2}(422)=1098.91, p<.000$, $\mathrm{CFI}=.96, \mathrm{RMSEA}=.03, \mathrm{SRMR}=.04, \Delta \chi^{2}(7)=12.06, p=10:$ the path coefficient for the subsample of younger employees was different from the path coefficients for the samples of middle-aged and senior employees.

Figure 1 shows the path coefficients for the final model in the different subsamples. Perceived occupational expertise related positively to perceived internal employability, and the relationships were similar in the subsample of younger $(\gamma=.50, p<.001)$, middle-aged $(\gamma=$ $.48, p<.001)$ and senior employees $(\gamma=.47, p<.001)$. Likewise, perceived occupational expertise related positively to perceived external employability, and relationships did not differ significantly in strength across the three groups $(\gamma=.69, p<.001$ for younger, $\gamma=.68, p<.001$ for middle-aged, and $\gamma=.56, p<.001$ for senior employees). Perceived internal employability was negatively related to job search intensity and, consistent with Hypothesis 3, this relationship was significantly stronger among younger employees $(\gamma=-.33, p<.001)$ in comparison with middle-aged $(\gamma=-.18, p<.001)$ and senior $(\gamma=-.15, p<.001)$ employees. Finally, perceived external employability related positively to job search intensity across all age groups $(\gamma=.19, p<.001$ for younger, $\gamma=.20, p<.001$ for middle-aged, and $\gamma=.19, p<$ .001 for senior employees). Hence, Hypothesis 4 was not supported.

\section{DISCUSSION}

The main objective of this study was to study the associations between employees' perceived occupational expertise, perceived internal employability and perceived external employability and job search intensity, including age as a possible moderator. In doing so, we made three important contributions. First, we exposed the management paradox by testing two opposite indirect associations between occupational expertise and job search intensity: a negative indirect association through perceived internal employability and a positive indirect 
association through perceived external employability. In line with our research model, the results for the total sample provided support for these conflicting dynamics: whilst occupational expertise was significantly and positively related to both perceived internal employability and perceived external employability, perceived internal employability related negatively, yet, perceived external employability related positively to job search intensity. These findings are in line with motivational theories, in particular the model of approach and avoidance achievement motivation (Elliott, 2005) and expectancy theory (Vroom, 1964). Employees base the perception of their value in the internal and external labor market on an evaluation of their personal strengths (i.e., their perceived occupational expertise) and in turn, this assessment will influence their decision whether or not to look for a job elsewhere. These results shed new light on the management paradox (De Cuyper and De Witte, 2011). While employees with occupational expertise are more likely to market their value elsewhere by looking for another job, their value within the internal labor market also ties them to their current organization.

Second, our study contributes to the employability literature by integrating different approaches of employability in one model, in particular the input (i.e., occupational expertise) and output (i.e., perceived employment opportunities) based approach. In doing so, it is one of the first studies to shed empirical light on the relationship between both approaches of employability (see Forrier et al., 2015; Wittekind et al., 2010 for exceptions). Our findings show that both are interrelated and form a chain: occupational expertise is positively associated with perceived internal employability and perceived external employability, the latter being a more proximal driver of job search than occupational expertise.

Third, we investigated whether the relationships between perceived internal employability and perceived external employability and job search intensity differed according to employee age. Although age has often been included as a covariate or confounder in previous 
research (Schalk et al., 2011), few researchers have explicitly studied age differences in the relationships between model variables (see for instance, De Lange et al., 2010; Van der Heijden et al., 2009). The pattern of results of our multi-group model test was different for perceived internal employability and perceived external employability. Age moderated the negative relationship between perceived internal employability and job search intensity suggesting that younger employees are more inclined to search for another job if they do not see opportunities within their employing organization compared with middle-aged and senior employees. This fits with the idea of socio-emotional selectivity theory (Carstensen et al., 1999) that younger individuals are more strongly driven by growth motives. It implies that the management paradox might particularly be a concern when considering younger workers: although managers might fear that investing in training and development makes them attractive for competitors, exactly the youngsters are highly appreciative of opportunities for further growth and development. Contrary to our expectations, age did not moderate the relationship between perceived external employability and job search. Our findings suggest that when employees believe to be valuable to other employers this will make them more likely to search for other jobs no matter what their age is. That is to say, the lack of perceived internal opportunities operates as a "push factor" for young employees to engage in job search, but perceived external opportunities operate as "pull factors" for young, middle-aged and senior employees alike. Possibly, the lack of internal opportunities will not be sufficient for middle-aged and senior employees to engage in job search as long as they find satisfaction in present relationships at work and generativity (Neugarten, 1977), yet in case they perceive attractive opportunities with other organizations, the possibility of furthering their career outside the organization might become more salient which might make them to be more inclined to engage in job search activities. 


\section{Limitations and Suggestions for Future Research}

Our study has some limitations that should be kept in mind when interpreting our results. First, despite the large sample size, all findings are based on cross-sectional, single-source data obtained from professional workers. Therefore, future research testing our hypotheses using a longitudinal multi-wave design may allow stronger conclusions, especially about stability and change with regard to the model variables and about cross-lagged relationships (De Lange et al., 2004; Taris and Kompier, 2003). Moreover, in such a design it is recommendable to not only include job search intensity but also actual turnover as an objective outcome measure.

Second, research into the generalizability of our outcomes to other employee groups and other countries is recommended, especially as we might assume that the prevalence and impact of moderating effects of age differs across cultures and institutional settings (Perry and Parlamis, 2005). Our findings regarding the moderating role of age might also be affected by the sample upon which our results are based, i.e., professional workers. As we collected data through a career magazine, a selection effect might explain why the association between perceived external employability and job search intensity was significant across age groups in our sample of respondents who are all visitors of this magazine's website. In particular the older respondents in our sample may, more strongly than the average older employee, be triggered by their external employability perceptions and translate these into job search behaviors. Further research is therefore needed to test for the external validity of our findings in other samples of employees.

Third, we looked at three age groups with varying sample sizes and this may have impacted the results and underestimated the effects for senior employees which were underrepresented in the sample. Although the age cut-off points for the three groups are in line with other studies (Van der Heijden, 2001; Van der Heijden et al., 2009), they are always somewhat arbitrary. Moreover, chronological age is only one way of looking at age. Future 
research might want to include different conceptualizations of age such as organizational age or subjective age (e.g., Sterns and Doverspike, 1989), as these conceptualizations might have distinct effects on the associations between perceived employability and job search behaviours.

\section{Practical Implications}

The management paradox is an often heard concern among human resource managers. Employers may be reluctant to invest in the development of their employees because they fear that they may easily lose such employees to competing organizations before they can recoup their investments (De Cuyper and De Witte, 2011). Our study highlights the importance of addressing internal job opportunities for employees as a vehicle to safeguard retention. Whilst employers cannot control employees' perceptions of opportunities in the external labor market, they can undertake actions in order to increase employees' perceptions of internal employability, for instance by providing perspectives for growth, fostering internal mobility, or simply by engaging in in-depth and honest career conversations during which individual and organizational needs can be aligned. While this is valuable for all age groups, it is of particular importance for young employees. After all, although employability perceptions are affected by occupational expertise for younger and older employees alike, in particular younger employees will engage in job search when they no longer feel employable in the internal labor market. It is therefore important to develop an age-considerate employability policy. Organizations can offer prospects to the young employees they wish to retain. At the same time, they should avoid creating a locked-in phenomenon of older workers staying despite a lack of internal opportunities by taking measures to ensure their sustainable employability, intrinsic motivation and engagement in the long run.

\section{REFERENCES}

Arbuckle, J. (2007), Amos 16.0 user's guide, SPSS, Chicagol IL. 
Arthur, M.B., Claman, P.H. and DeFillippi, R.J. (1995), "Intelligent enterprise, intelligent careers", The Academy of Management Executive, Vol. 9 No. 4, pp. 7-20

Bal, P.M., De Lange, A.H., Zacher, H. and Van der Heijden, B.I.J.M. (2013), “A lifespan perspective on psychological contracts and their relations with organizational commitment", European Journal of Work and Organizational Psychology, Vol. 22 No. 3, pp. 279-292.

Blau, G. (1994), “Testing a two-dimensional measure of job search behavior”. Organizational behavior and human decision processes, Vol. 59 No. 2, pp. 288-312.

Carlson K.D. and Wu, J. (2012), "The illusion of statistical control: Control variable practice in management research", Organizational Research Methods, Vol. 15 No. 3, pp. 413-435.

Carstensen, L.L., Isaacowitz, D.M. and Charles, S.T. (1999), "Taking time seriously: A theory of socioemotional selectivity", American Psychologist, Vol. 4 No. 3, pp. 165-181.

Chen, D.J.Q. and Lim, V.K.G. (2012), ”Strength in adversity: The influence of psychological capital on job search”, Journal of Organizational Behavior, Vol. 33, No. 6, pp. 811-839.

De Coen, A., Forrier, A., \& Sels, L. (2015). The impact of age on the reservation wage: the role of employment efficacy and work intention: a study in the Belgian context. Journal of Applied Gerontology, 34(3), NP83-NP112.

De Cuyper, N. and De Witte, H. (2011), “The management paradox: Self-rated employability and organizational commitment and performance", Personnel Review, Vol. 40, No.2, pp. $152-172$.

De Cuyper, N., Mauno, S., Kinnunen, U. and Mäkikangas, A. (2011), "The role of job resources in the relation between perceived employability and turnover intention: A prospective two-sample study", Journal of Vocational Behavior, Vol. 78, No. 2, pp. 253263.

De Cuyper, N., Van der Heijden, B.I.J.M. and De Witte, H. (2011), “Associations between perceived employability, employee well-being, and its contributions to organizational 
success: A matter of psychological contracts?" The International Journal of Human Resource Management, Vol. 22, No. 7, pp. 1486-1503.

De Lange, A.H., Taris, T.W., Jansen, P.G.W., Kompier, M.A.J., Houtman, I.L.D. and Bongers, P.M. (2010), "On the relationships among work characteristics and learning-related behavior: does age matter?” Journal of Organizational Behavior, Vol. 31, No. 7, pp. 925950.

De Vos, A., De Hauw, S. and Van der Heijden, B.I.J.M. (2011), “Competency development and career success. The mediating role of employability", Journal of Vocational Behavior, Vol. 79 No. 2, pp. 438-447.

Eby, L.T., Butts, M. and Lockwood, A. (2003), "Predictors of success in the era of the boundaryless career", Journal of Organizational Behavior, Vol. 24 No. 6, pp. 689-708.

Elliot, A.J. (2005), “A conceptual history of the achievement goal construct”. In Elliot, A.J. and Dweck C.S. (Eds.), Handbook of Competence and Motivation, The Guilford Press, New York, pp. 52-72.

European Commission (2015), The 2015 Ageing Report. Economic and budgetary projections for the 28 EU Member States (2013-2016), European Commission, Brussels.

Feldman, D. C. (2007). Career mobility and career stability among older workers. In K.S. Schultz \& K A/ Adams (Ed.) Aging and work in the 21st century (pp. 179-197). Mahwah, NJ: Lawrence Erlbaum.

Forrier, A. and Sels, L. (2003), “The concept employability: A complex mosaic”, International Journal of Human Resource Development and Management, Vol. 3, No. 2, pp. 103-124.

Forrier, A., Sels, L. and Stynen, D. (2009), "Career mobility at the intersection of between agent and structure: A conceptual model”, Journal of Occupational and Organizational Psychology, Vol. 82, No. 4, pp. 739-759. 
Forrier, A., Verbruggen, M., De Cuyper, N. (2015), "Integrating different notions of employability in a dynamic chain: The relationship between job transitions, movement capital and perceived employability", Journal of Vocational Behavior, Vol. 89, pp. 56-64.

Griffeth, R.W., Hom, P. and Gaertner, S. (2000), "A Meta-Analysis of antecedents and correlates of employee turnover: update, moderator tests, and research implications for the next millennium", Journal of Management, Vol. 26, No. 3, pp. 463-488.

Griffeth, R.W., Steel, R.P., Allen, D.G. and Bryan, N. (2005), "The development of a multidimensional measure of job market cognitions: the Employment Opportunity Index (EOI)", Journal of Applied Psychology, Vol. 90 No. 2, pp. 335-349.

Hu, L.T. and Bentler, P.M. (1999), "Cutoff criteria for fit indexes in covariance structure analysis: Conventional criteria versus new alternatives", Structural Equation Modeling: A Multidisciplinary Journal, Vol. 6 No. 1, pp. 1-55.

Hunt, J. and Collins, R.R. (1983), Managers in Mid Career Crisis. Wellington Lane Press, Sidney.

Kooij, D.T., De Lange, A.H., Jansen, P.G., Kanfer, R. and Dikkers, J. S. (2011), “Age and work-related motives: Results of a meta-analysis". Journal of Organizational Behavior, Vol. 32 No. 2, pp. 197-225.

Maehr, M.L. and Kleiber, D.A. (1981), “The graying of achievement motivation”, American Psychologist, Vol. 36, No. 7, pp. 787-793.

Nauta, A., Van Vianen, A., Van der Heijden, B.I.J.M. Van Dam, K. and Willemsen, M. (2009), "Understanding the factors that promote employability orientation: The moderating impact of employability culture", Journal of Occupational and Organizational Psychology, Vol. 82, No. 2, pp. 233-251. 
Neugarten, B.L. (1977), "Personality and aging”, in Craik, F.I.M., Birren, J.E. and Schaie, K.W., Handbook of the Ppsychology of Aging. Van Nostrand Rheinhold, New York, pp. $626-649$.

Ng, T.W. and Feldman, D.C. (2009), "Re-examining the relationship between age and voluntary turnover", Journal of Vocational Behavior, Vol. 74 No. 3, pp. 283-294.

Orth, U, Robins, R.W. and Widaman, K.F. (2012), "Life-span development of self-esteem and its effects on important life outcomes”, Journal of Personality and Social Psychology, Vol. 102, No. 6, pp. 1271-1288.

Peeters, M. C. and van Emmerik, H. (2008), “An introduction to the work and well-being of older workers: From managing threats to creating opportunities”, Journal of Managerial Psychology, Vol. 23 No. 4, pp. 353-363.

Perry, E.L. and Parlamis, J.D. (2005), “Age and ageism in organizations: A review and consideration of national culture", in Konrad, A. M., Prasad, PP. and Pringle, J. K. (Eds), Handbook of Workplace Diversity, Sage, London, UK, pp 345-370.

Rothwell, A. and Arnold, J. (2007), "Self-perceived employability: Development and validation of a scale", Personnel Review, Vol. 36, Vol. 1, pp. 23-41.

Schalk, R., Van Veldhoven, M., De Lange, A.H., De Witte, H., Kraus, K., Stamov-Rossnagel, C. et al. (2010), "Moving European research on work and ageing forward: Overview and agenda", European Journal of Work and Organizational Psychology, Vol. 19, No. 1, pp. 76-101.

Spector P.E. and Brannick M.T. (2011), "Methodological urban legends: The misuse of statistical control variables”, Organizational Research Methods, Vol. 14 No. 2, pp. 287305. 
Sterns, H. L. and Doverspike, D. (1989), "Aging and the retraining and learning process in organizations", in Goldstein, I. and Katzel, R. (Eds.), Training and Development in Work Organizations, Jossey-Bass, San Francisco, CA, pp. 229-332.

Taris, T. W. and Kompier, M. (2003), "Challenges of longitudinal designs in occupational health psychology", Scandinavian Journal of Work, Environment and Health, Vol. 29, No. 1, pp. 1-4.

Van der Heijden, B.I.J.M. (2000), "The development and psychometric evaluation of a multidimensional measurement instrument of professional expertise", High Ability Studies: The Journal of the European Council for high ability, Vol. 11 No. 1, pp. 9-39.

Van der Heijden, B.I.J.M. (2001), “Age and assessments of professional expertise. The relationship between higher level employees' age and self-assessments or supervisor ratings of professional expertise”, International Journal of Selection and Assessment, Vol. 9 No. 4 , pp. 309-324.

Van der Heijden, B.I.J.M. (2002), "Individual career initiatives and their influence upon professional expertise development throughout the career", International Journal of Training and Development, Vol. 6 No. 2, pp. 54-79.

Van der Heijden, B.I.J.M., De Lange, Demerouti, E. and Van der Heijde, C.M. (2009), "Employability and Career Success Across the Life-Span. Age Effects on the Employability-Career Success Relationship”, Journal of Vocational Behavior, Vol. 74, No. 2, pp. 156-164.

Van der Heijde, C.M. and Van der Heijden, B.I.J.M. (2006), "A competence-based and multidimensional operationalization and measurement of employability", Human Resource Management, Vol. 45, No. 3, pp. 449-476.

Vanhercke, D., De Cuyper, N., Peeters, E. and De Witte, H. (2014), “Defining perceived employability: A psychological approach”, Personnel Review, Vol. 43, pp. $592-605$. 
Van Hooft, E. A., Born, M. P., Taris, T. W., Flier, H. V. D., \& Blonk, R. W. (2004). Predictors of job search behavior among employed and unemployed people. Personnel Psychology, 57(1), 25-59.

Vroom, V. H. (1964), Work and Motivation, John Willey \& Sons, New York.

Williams, S., Dodd, L. J., Steele, C. and Randall, R. (2015). “A systematic review of current understandings of employability", Journal of Education and Work, Vol. 29, No. 8, pp. 1-25.

Wittekind, A., Raeder, S. and Grote, G. (2010), “A longitudinal study of determinants of employability”, Journal of Organizational Behavior. Vol. 31, No. 4, pp. 566-586. 
Table 1. Means, Standard Deviations and Correlations (Cronbach's Alpha between Brackets) for the Total Sample (normal font; $N=2137$ ) and the Subsamples of Younger Workers (in italic; $\mathrm{N}=1003$ ), Middle-aged (in bold; $\mathrm{N}=893$ ) and Senior Workers (underlined; $\mathrm{N}=241$ ).

\begin{tabular}{|c|c|c|c|c|c|c|}
\hline & M & SD & 1 & 2 & 3 & 4 \\
\hline \multirow[t]{4}{*}{ 1. Occupational expertise } & 4.19 & .48 & $(.79)$ & & & \\
\hline & 4.06 & .48 & $(.76)$ & & & \\
\hline & 4.29 & .45 & (.79) & & & \\
\hline & $\underline{4.37}$ & .46 & $(.81)$ & & & \\
\hline \multirow[t]{4}{*}{ 2. Perceived internal employability } & 3.68 & .73 & $.33 * * *$ & $(.76)$ & & \\
\hline & 3.64 & .73 & $.30 * * *$ & $(.77)$ & & \\
\hline & 3.71 & .74 & $.36 * * *$ & $(.79)$ & & \\
\hline & $\underline{3.67}$ & .70 & $.43 * * *$ & $(.78)$ & & \\
\hline \multirow[t]{4}{*}{ 3. Perceived external employability } & 3.76 & .67 & $.41 * * *$ & $.39 * * *$ & $(.67)$ & \\
\hline & 3.74 & .67 & $.41 * * *$ & $.32 * * *$ & $(.66)$ & \\
\hline & 3.80 & .66 & $.45 * * *$ & $.44 * *$ & (.70) & \\
\hline & $\underline{3.68}$ & .65 & $.41 * * *$ & $.53 * * *$ & $(.65)$ & \\
\hline \multirow[t]{4}{*}{ 4. Job search intensity } & 1.85 & .94 & .02 & $-.15 * * *$ & $.05^{*}$ & $(.92)$ \\
\hline & 1.87 & .95 & -.03 & $-.23 * * *$ & -.01 & $(.92)$ \\
\hline & 1.81 & .91 & $.10 *$ & $-.10 * * *$ & $.11 *$ & (.92) \\
\hline & 1.91 & 1.01 & .06 & .02 & .09 & $(.95)$ \\
\hline \multirow[t]{4}{*}{ 5. Age } & 37.18 & 8.83 & $.27 * * *$ & .03 & .00 & -.01 \\
\hline & 29.55 & 2.81 & $.12 * * *$ & .07 & .08 & $-.13 * * *$ \\
\hline & 41.34 & 4.33 & $.10 * * *$ & -.02 & -.06 & .04 \\
\hline & 53.56 & 3.80 & -.04 & -.07 & -.05 & -.01 \\
\hline
\end{tabular}

$* p<.05, * * p<.01, * * * p<.001$ 
Table 2. Measurement Models for the Total Sample (upper part) and Subsamples (lower part).

\begin{tabular}{|c|c|c|c|c|c|c|c|c|c|c|}
\hline & Model description & $\mathrm{X}^{2}$ & df & $\mathrm{p}$ & CFI & RMSEA & SRMR & Model comparison & $\Delta \chi^{2}$ & $\mathrm{df}$ \\
\hline MM1 & $\begin{array}{l}\text { OE } \\
\text { PIE } \\
\text { PEE } \\
\text { JSI }\end{array}$ & 622.97 & 129 & $<.000$ & .97 & .04 & .03 & & & \\
\hline MM2 & $\begin{array}{l}\text { OE } \\
\text { PIE + PEE } \\
\text { JSI }\end{array}$ & 1471.58 & 132 & $<.000$ & .92 & .07 & .07 & MM2 - MM1 & $848.61^{* * *}$ & 3 \\
\hline MM3 & $\mathrm{OE}+\mathrm{PIE}+\mathrm{PEE}+\mathrm{JSI}$ & 11421.32 & 135 & $<.000$ & .52 & .20 & .21 & MM3 - MM1 & $10798.35 * * *$ & 6 \\
\hline MM4 & Configural model & 935.38 & 387 & $<.000$ & .97 & .03 & .04 & & & \\
\hline MM5 & Factorial invariance & 1004.58 & 415 & $<.000$ & .96 & .03 & .04 & MM5-MM4 & $69.2 * * *$ & 28 \\
\hline MM6 & Final model & 974.31 & 409 & $<.000$ & .97 & .03 & .04 & MM6-MM4 & $38.93, p=.014$ & 22 \\
\hline
\end{tabular}

$* * * p<.001 ; \mathrm{OE}=$ Occupational Expertise PIE = Perceived Internal Employability; PEE = Perceived External Employability; JSI = Job Search Intensity 
Table 3. Structural Models for the Total Sample (upper part) and Multi-Group Analysis (lower part)

\begin{tabular}{|c|c|c|c|c|c|c|c|c|c|c|}
\hline & Model description & $\mathrm{X}^{2}$ & $\mathrm{df}$ & $\mathrm{p}$ & CFI & RMSEA & SRMR & Model comparison & $\Delta \chi^{2}$ & df \\
\hline SM1 & Direct + indirect effects & 733.10 & 130 & $<.000$ & .96 & .05 & .04 & & & \\
\hline SM2 & Indirect effects & 733.37 & 131 & $<.000$ & .96 & .05 & .04 & SM2 - SM1 & $.27, p=.60$ & 1 \\
\hline SM4 & Unconstrained model & 1086.85 & 415 & $<.000$ & .96 & .03 & .04 & & & \\
\hline SM5 & Constrained model & 1109.56 & 423 & $<.000$ & .96 & .03 & .04 & SM5 - SM4 & $22.71 * *$ & 8 \\
\hline SM6 & Final model & 1098.91 & 422 & $<.000$ & .96 & .03 & .04 & SM6 - SM4 & $12.06, p=.10$ & 7 \\
\hline
\end{tabular}

$* * p<.01$ 